\title{
Complexity: a new paradigm for fracture mechanics
}

\author{
A. Carpinteri, S. Puzzi \\ Politecnico di Torino, Department of Structural and Geotechnical Engineering, Corso Duca degli Abrurzi 24, 10129 Torino, \\ Italy, alberto.carpinteri@polito.it; simone.puzzi@polito.it
}

RiAssunTO. Le cosiddette Scienze della Complessità sono un argomento di interesse in forte crescita all'interno della Comunità Scientifica. In realtà, i ricercatori non sono ancora giunti ad un'unica definizione di Complessità, per il fatto che essa si manifesta attraverso svariate forme [1]. Questo campo d'indagine, infatti, non è rappresentato da una singola disciplina, ma piuttosto da un insieme eterogeneo costituito da differenti tecniche matematiche e da diversi ambiti della scienza. Sotto l'allocuzione di Scienze della Complessità comprendiamo una grande varietà di approcci: la dinamica non lineare, la teoria del caos deterministico, la termodinamica del non-equilibrio, la geometria frattale, l'asintoticità intermedia, l'autosomiglianza completa ed incompleta, la teoria del gruppo di rinormalizzazione, la teoria delle catastrofi, la criticalità auto-organizzata, le reti neurali, gli automi cellulari, la logica sfumata (fuzzy logic), etc.

Scopo del presente lavoro è quello di approfondire il ruolo della Complessità nel campo della Scienza dei Materiali e della Meccanica della Frattura [2-3]. Gli esempi presentati riguarderanno il fenomeno instabile dello snap-back nel comportamento di strutture composite (Carpinteri [4-6]), l'insorgere di pattern frattali e dell'autosomiglianza nella deformazione e nel danneggiamento dei materiali eterogenei, oltre agli effetti di scala sulle proprietà meccaniche nominali dei materiali disordinati (Carpinteri $[7,8])$. Ulteriori esempi si occuperanno dell'interpretazione dei fenomeni critici e degli effetti di scala temporale sulla vita ultima delle strutture per mezzo della Emissione Acustica (Carpinteri et al.[9]). Infine, verranno presentati risultati sulla transizione verso il caos nel comportamento dinamico di travi fessurate (Carpinteri and Pugno [10,11]).

ABSTRACT. The so-called Complexity Sciences are a topic of fast growing interest inside the scientific community. Actually, researchers did not come to a definition of complexity, since it manifests itself in so many different ways [1]. This field itself is not a single discipline, but rather a heterogeneous amalgam of different techniques of mathematics and science. In fact, under the label of Complexity Sciences we comprehend a large variety of approaches: nonlinear dynamics, deterministic chaos theory, nonequilibrium thermodynamics, fractal geometry, intermediate asymptotics, complete and incomplete similarity, renormalization group theory, catastrophe theory, self-organized criticality, neural networks, cellular automata, fuzzy logic, etc.

Aim of this paper is at providing insight into the role of complexity in the field of Materials Science and Fracture Mechanics [2-3]. The presented examples will be concerned with the snap-back instabilities in the structural behaviour of composite structures (Carpinteri [4-6]), the occurrence of fractal patterns and selfsimilarity in material damage and deformation of heterogeneous materials, and the apparent scaling on the nominal mechanical properties of disordered materials (Carpinteri $[7,8])$. Further examples will deal with criticality in the acoustic emissions of damaged structures and with scaling in the time-to-failure (Carpinteri et al. [9]). Eventually, results on the transition towards chaos in the dynamics of cracked beams will be reported (Carpinteri and Pugno [10,11]).

KEYwORDS. Catastrophe Theory, Fractal Geometry, Scaling of Material Properties, Self-Organized Criticality, Deterministic Chaos. 


\section{INTRODUCTION}

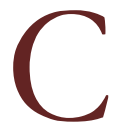

omplexity, as a discipline, generally refers to the study of large-scale systems with many interacting components, in which the overall system behaviour is qualitatively different from (and not encoded in) the behaviour of its components. Complex systems lie somehow in between perfect order and complete randomness -the two extreme conditions that occur only very seldom in nature- and exhibit one or more common characteristics, such as: sensitivity to initial conditions, pattern formation, spontaneous self-organization, emergence of cooperation, hierarchical or multiscale structure, collective properties beyond those directly contained in the parts, scale effects. Complexity has two distinct and almost opposite meanings: the first goes back to Kolmogorov's reformulation of probability and his algorithmic theory of randomness via a measure of complexity, now referred to as Kolmogorov Complexity [1]; the second to the Shannon's studies of communication channels via his notion of information. In both cases, complexity is a synonym of disorder and lack of a structure: the more random a process is, the more complex it results to be. The second meaning of complexity refers instead to how intricate, hierarchical, structured and sophisticated a process is. Associated with these two almost opposite meanings, are two natural trends of composite systems, and two corresponding questions: how does order and structure emerge from large, complicated systems? And, conversely, how do randomness and chaos arise from systems with only simple constituents, whose behaviour does not directly encode randomness? The former case is typical of all those phenomena which could be described through the concepts of scale invariance, phase transition, and with the use of power laws. The latter case is that of instability and bifurcations and of dynamical systems showing chaotic attractors and transition to chaos. In this paper, several fracture mechanics applications will be shown, in which both trends are present.

\section{THE NONLINEAR COHESIVE CRACK MODEL: SNAP-BACK INSTABILITY AS A CUSP CATASTROPHE}

1 he first example dates back to the 1980's, when the senior author [4-6] approached the snap-back instability of cracked bodies with a Cohesive Crack model, which can be interpreted in the general framework of Catastrophe Theory (Thom [12]). This first section is thus devoted to a brief review of the ductile-to-brittle transition in the mechanical behaviour of cracked solids, described by means of the Cohesive Crack model.

The Cohesive Crack Model was initially proposed by Barenblatt [13] and Dugdale [14]. Subsequently, Dugdale's model was reconsidered by several other Authors (for a review see [15]); Hillerborg et al. [16] proposed the Fictitious Crack Model in order to study crack propagation in concrete. The cohesive crack model is based on the following assumptions $([4,15])$ :

1. The cohesive fracture zone (plastic or process zone) begins to develop when the maximum principal stress achieves the ultimate tensile strength $\sigma_{\mathrm{u}}$.

2. The material in the process zone is partially damaged but still able to transfer stress. Such a stress is dependent on the crack opening displacement $w$. The energy $G_{\mathrm{F}}$ necessary to produce a unit crack surface is given by the area under the $\sigma-w$ diagram.

The real crack tip is defined as the point where the distance between the crack surfaces is equal to the critical value of crack opening displacement $w_{\mathrm{c}}$ and the normal stress vanishes. On the other hand, the fictitious crack tip is defined as the point where the normal stress attains the maximum value and the crack opening vanishes (Fig. 1). With some modifications, the cohesive crack model has been applied to model a wide range of materials and fracture mechanisms, most prominently concrete. Regarding this material, there is a very large literature; for a review, the reader is referred to the review papers by Carpinteri and co-workers $[15,17]$. Now, let us quantify the ductile-to-brittle transition by showing synthetically the numerical results for concrete elements in Mode I conditions (Three Point Bending Test - TPBT), based on the cohesive model, obtained using the Finite Element Code FR.ANA. (FRacture ANAlysis Carpinteri [5,18,19]).

Extensive series of analyses were carried out from 1984 to 1989 by A. Carpinteri and co-workers. The experimental results can be found in the RILEM report [20]. The cases described in the reference papers regard three slenderness ratios, and four initial crack depths, and a concrete-like material. Fig. 2a refers to the case of an initially uncracked beam, whilst Fig. $2 \mathrm{~b}$ reports results for the case of an initially cracked beam with relative crack depth equal to 0.5.

For each ratio, the response was analyzed for different values of the brittleness number, $S_{\mathrm{E}}$ [4]. As can be seen from the diagrams, by increasing $S_{\mathrm{E}}$ the behaviour of the element changes from brittle to ductile. Generally speaking, the specimen behaviour is brittle (snap-back) for low $S_{\mathrm{E}}$ numbers, i.e., for low fracture toughness, $G_{\mathrm{F}}$, high tensile strengths, $\sigma_{\mathrm{u}}$, and/or large sizes, $h$. In particular, in the case of uncracked beam, for $S_{\mathrm{E}} \lesssim 10.45 \times 10^{-5}$, the $P-\delta$ curve presents positive slope in the 
softening branch and a catastrophical event occurs if the loading process is deflection-controlled. Such indenting branch is not virtual only if the loading process is controlled by a monotonically increasing function of time (Biolzi et al. [21]).

(a)

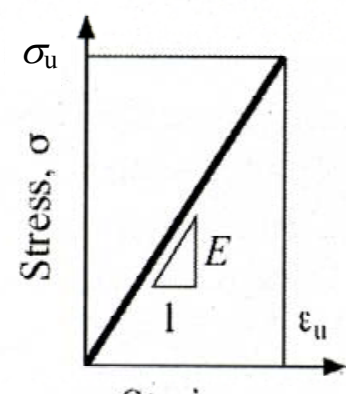

Strain, $\varepsilon$ (b)

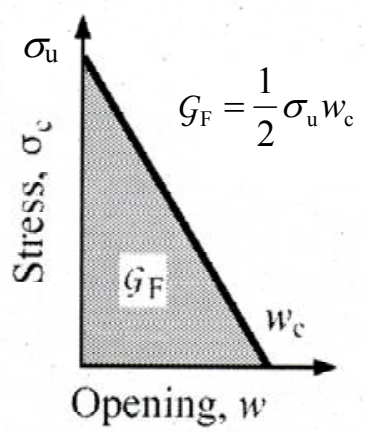

Figure 1: Constitutive laws of the cohesive crack model: (a) undamaged material; (b) process zone.

In the case of the cracked beam, on the contrary, the initial crack makes the specimen behaviour more ductile; for the set of $S_{E}$ numbers considered in Fig. 2b, the snap-back does not occur. By varying the initial crack depth, it is possible to describe the gradual transition from simple fold catastrophe (softening) to bifurcation or cusp catastrophe (snap-back instability), generating an entire equilibrium surface, or the catastrophe manifold.
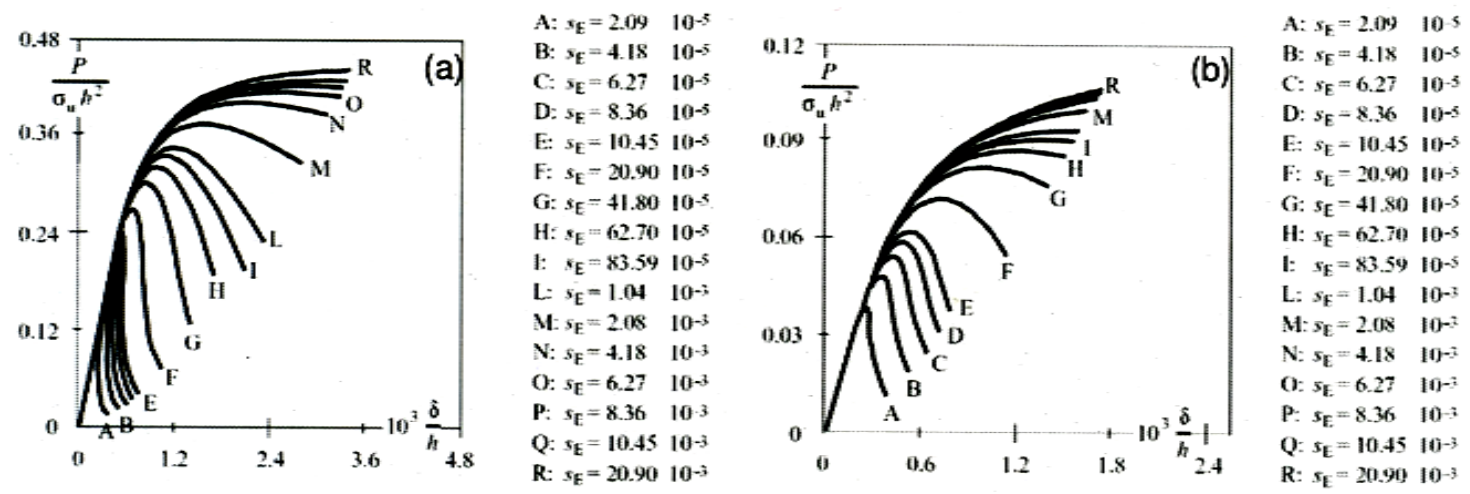

Figure 2: Dimensionless load vs. deflection diagrams by varying the brittleness number $S_{E}$, initially uncracked (a) and cracked (b) specimen

\section{THE FRACTAL INTERPRETATION OF THE SIZE-SCALE EFFECT}

he second topic is concerned with the size-scale effects on the mechanical properties of heterogeneous disordered materials that can be interpreted synthetically through the use of fractal sets. Fractal sets are characterized by noninteger dimensions (Mandelbrot [22]). For instance, the dimension $\alpha$ of a fractal set in the plane can vary between 0 and 2. Accordingly, increasing the measure resolution, its length tends to zero if its dimension is smaller than 1 or tends to infinity if it is larger. In these cases, the length is a nominal, useless quantity, since it diverges or vanishes as the measure resolution increases. A finite measure can be achieved only using noninteger units, such as meters raised to $\alpha \neq 1$.

Fractals sets can be profitably used to describe the size-scale effects on the parameters of the cohesive crack model. As shown in the previous section, this model captures the ductile-brittle transition occurring by increasing the size of the structure. On the other hand, uniaxial tensile tests on dog-bone shaped specimens $[23,24]$ have shown that the three material parameters defining the cohesive law are size dependent: increasing the specimen size, the tensile strength $\sigma_{\mathrm{u}}$, tends to decrease, whilst the fracture energy $G_{\mathrm{F}}$ and the critical displacement $w_{\mathrm{c}}$ increase. In order to overcome the original cohesive crack model drawbacks, a scale-independent (fractal) cohesive crack model has been proposed recently by the first Author [25]. This model is based on the assumption of a fractal-like damage localization, suggested by experimental evidence $[26,27]$. 
Let us consider fractal geometries for both the resistant cross section at maximum load (Fig. 3a) and the dissipation domain (Fig. 3c) [25]. Hence we can compute the maximum load F, the critical displacement $w_{c}$ and the total dissipated energy $W$ as:

$$
\begin{aligned}
& F=\sigma_{\mathrm{u}} \mathrm{A}_{0}=\sigma_{\mathrm{u}}^{*} \mathrm{~A}_{\text {res }}^{*} \\
& W_{c}=\varepsilon_{c} b=\varepsilon_{c}^{*} b^{1-d_{\varepsilon}} \\
& W=G_{\mathrm{F}} \mathrm{A}_{0}=G_{\mathrm{F}}^{*} \mathrm{~A}_{\text {dis }}^{*}
\end{aligned}
$$

These quantities are size-dependent. The true scale-independent quantities are the right hand side ones, i.e. the fractal strength $\sigma_{\mathrm{u}}^{*}$, the fractal critical strain $\varepsilon_{c}^{*}$ and the fractal fracture energy $G_{\mathrm{F}}{ }^{*}$. They show non-integer physical dimensions: $[\mathrm{F}][\mathrm{L}]^{-(2-d \sigma)}$ for $\sigma_{\mathrm{u}^{*}},[\mathrm{~L}]^{(d)}$ for $w_{\mathrm{c}}$ and $[\mathrm{FL}][\mathrm{L}]^{-(2+d G)}$ for $G_{\mathrm{F}}{ }^{*}$. Because of the measure of the resistant cross section $\mathrm{A}_{\mathrm{res}}$ and the dissipation domain $A_{\text {dis, }}$ from Eqs. (1) the scaling laws for strength, critical displacement and fracture energy can be obtained:

$$
\begin{aligned}
& \sigma_{\mathrm{u}}=\sigma_{\mathrm{u}}^{*} b^{-d_{\sigma}} \\
& w_{c}=\varepsilon_{c}^{*} b^{1-d_{\varepsilon}} \\
& G_{\mathrm{F}}=G_{\mathrm{F}}^{*} b^{+d_{G}}
\end{aligned}
$$
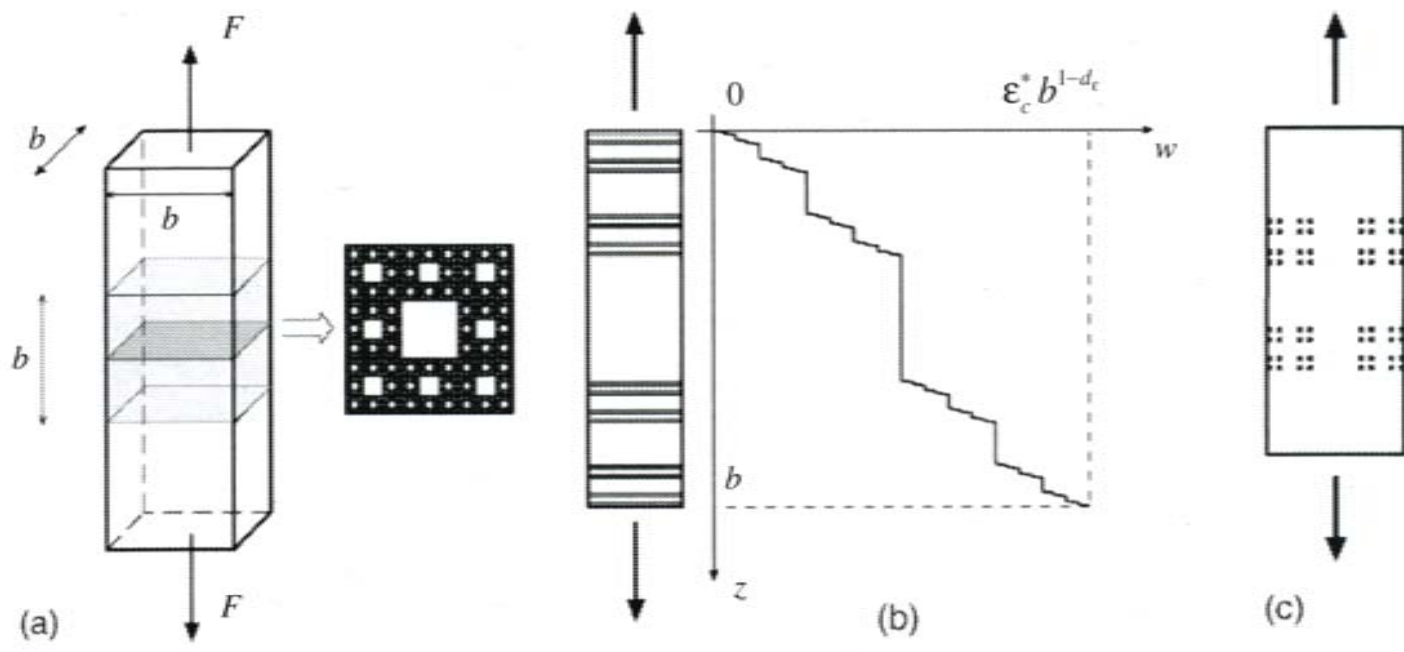

(c)

Figure 3: A concrete specimen subjected to tension. Fractal localization of the resistant cross section (a); fractal localization of the strain (b) and the energy dissipation inside the damaged band (c).

The three size effect laws (2) of the cohesive law parameters are not completely independent of each other. In fact, there is a relation among the scaling exponents that must be always satisfied. In order to get this relation, the simplest path is to consider the damage domain in Fig. $3 \mathrm{c}$ as the cartesian product of those in Figs. 3a and 3b. As a result, we obtain:

$$
d_{\sigma}+d_{\varepsilon}+d_{G}=1
$$

According to these definitions, we call the $\sigma^{*}-\varepsilon^{*}$ diagram the fractal or scale-independent cohesive law. Contrarily to the classical cohesive law, which is experimentally sensitive to the structural size, this curve is an exclusive property of the material since it is able to capture the fractal nature of the damage process. The area below the softening fractal stressstrain diagram represents the fractal fracture energy $G_{\mathrm{F}}{ }^{*}$.

In order to validate the model, it has been applied to the data obtained in 1994 by Carpinteri and Ferro [23,24] for tensile tests on dog-bone shaped concrete specimens of various sizes under controlled boundary conditions (Fig. 4a). They 
interpreted the size effects on the tensile strength and the fracture energy by fractal geometry. Fitting the experimental results, they found the values $d_{\sigma}=0.14$ and $d_{\mathrm{G}}=0.38$. Some of the $\sigma-\varepsilon$ (stress vs. strain) and $\sigma-w$ diagrams are reported respectively in Fig. $4 \mathrm{~b}$ and $4 \mathrm{c}$, where $w$ is the displacement localized in the damaged band. Eq. (3) yields $d_{\varepsilon}=0.48$, so that the fractal cohesive laws can be plotted in Fig. 4d. As expected, all the curves related to the single sizes tend to merge in a unique, scale-independent cohesive law. The overlapping of the cohesive laws for the different sizes proves the soundness of the fractal approach to the interpretation of concrete size effects.

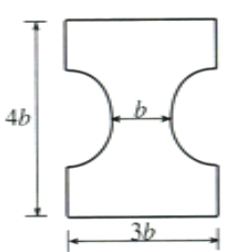

(a)
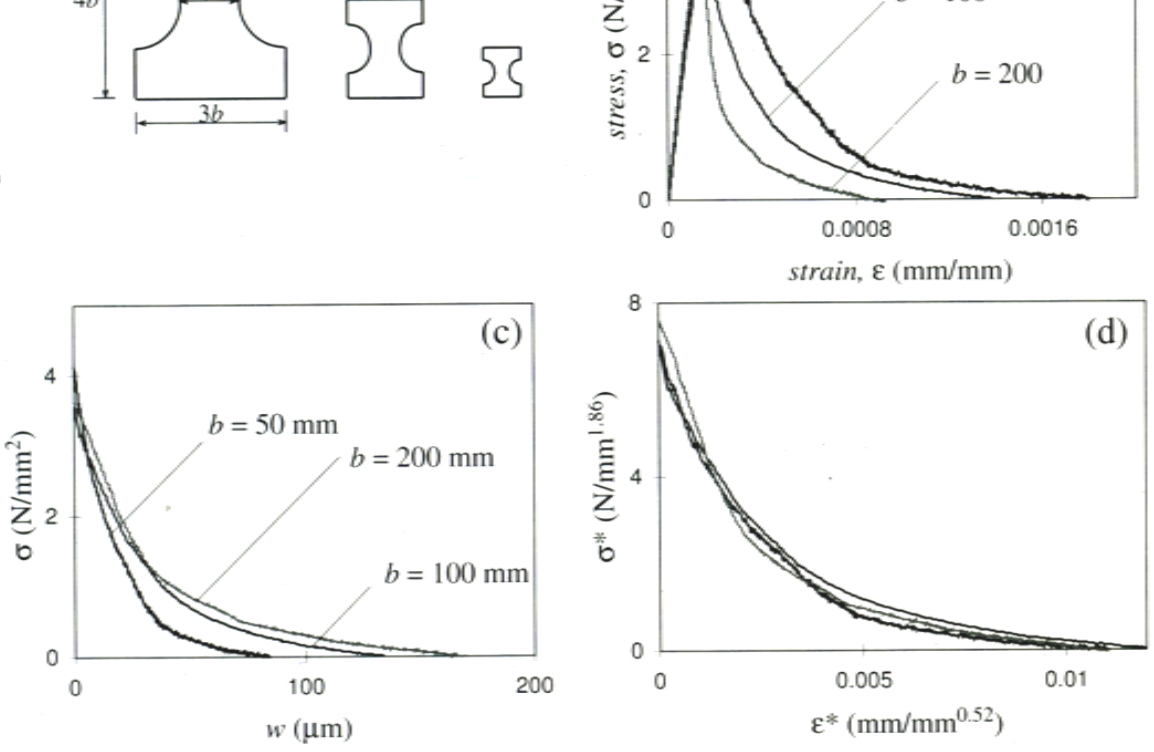

Figure 4: Tensile test on dog-bone shaped specimens (a) by Carpinteri and Ferro [28]; stress-strain diagrams (b), cohesive law diagrams (c), fractal cohesive law diagrams (d).

\section{THE FRACTAL INTERPRETATION OF MULTISCALE CRACKING PHENOMENA}

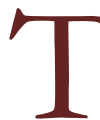
he third topic deals with the criticality of the complex multiscale cracking phenomena in heterogeneous and disordered materials, evaluated by means of the Acoustic Emission (AE) technique. Acoustic Emission (AE) is represented by the class of phenomena whereby transient elastic waves are generated by the rapid release of energy from localized sources within a material. All materials produce AE during both the generation and propagation of cracks. The elastic waves move through the external solid surface, where they are detected by sensors. In this way, information about the existence and location of possible damage sources is obtained. This is similar to seismicity, where seismic waves reach the station placed on the earth surface (Richter [28]).

With regard to the basis of AE research in concrete, the early scientific papers were published in the 1960s. Particularly interesting are the contributions by Rusch [29], L'Hermite [30] and Robinson [31]. They discussed the relation between fracture process and volumetric change in the concrete under uniaxial compression. The most important applications of AE to structural concrete elements started in the late 1970s [32]. Regarding the determination of the defects position and orientation in the material, research has been growing at a fast rate in the last decade (Shah \& Zongjing [33] and Ohtsu [34]). In the last few years the $\mathrm{AE}$ technique has been applied to identify defects and damage in reinforced concrete structures and masonry buildings (Carpinteri \& Lacidogna [35,36]). By means of this technique, a particular methodology has been put forward for crack propagation monitoring and crack stability assessment in structural elements under service conditions. This technique permits to estimate the amount of energy released during fracture propagation and to obtain information on the criticality of the ongoing process [9,37].

Without entering the details, recent developments in fragmentaron theories (Carpinteri \& Pugno [38,39]) have shown that the energy dissipation $E$ during microcrack propagation occurs in a fractal domain comprised between a surface and the 
specimen volume $V$. The fractal criterion predicts a volume-effect on the maximum number of acoustic emission events $N_{\max }$, that, in a bilogarithmic diagram, would appear as:

$$
\log N_{\max }=\log \Gamma_{A E}+\frac{D}{3} \log \mathrm{V}
$$

with a slope equal to $D / 3$, where $\Gamma_{\mathrm{AE}}$ is the critical value of fractal acoustic emission density and $D$ is the fractal exponent, comprised between 2 and 3 [37]. Experiments carried out by Carpinteri et al. [36] on concrete specimens tested in compression confirm the soundness of the proposed approach. For all the tested specimens, the critical number of acoustic emissions $N_{\max }$ was evaluated in correspondence to the peak-stress $\sigma_{u}$. The compression tests show an increase in $\mathrm{AE}$ cumulative event number by increasing the specimen volume. More in detail, subjecting the average experimental data to a statistical analysis, the parameters $D$ and $\Gamma_{\mathrm{AE}}$ in eq. (4) were quantified. From the best-fitting, reported graphically in Fig. 5, the estimated value of the slope was computed as $D / 3=0.766$, so that, as predicted by the fragmentation theories, $2 \leq D \geq 3$. This result is a confirmation of the fact that the energy dissipation, measured by the number of acoustic emissions $N$, occurs over a fractal domain. Interestingly, the criticality of the cracking phenomena does appear not only in space, but also in time. A scaling relation of the type of eq. (4) can be written for the time $t$, allowing one to define the damage parameter $\eta$, which can be expressed $[9,37]$ as a function of different parameters, i.e., stress $\sigma$, strain $\varepsilon$ or time $t$.

$$
\eta=\frac{N}{N_{\max }}=\left(\frac{\sigma}{\sigma_{\max }}\right)^{\beta_{\sigma}}=\left(\frac{\varepsilon}{\varepsilon_{\max }}\right)^{\beta_{\varepsilon}}=\left(\frac{t}{t_{\max }}\right)^{\beta_{\mathrm{t}}}
$$

where the exponents $\beta$ can be obtained from the AE data of a reference specimen. The fractal multiscale criterion of Eq. (5) is a fundamental result, since it allows to predict the damage evolution also in large concrete structural elements. Monitoring the damage evolution by AE, it is therefore possible to evaluate the damage level as well as the time to the final collapse [9].

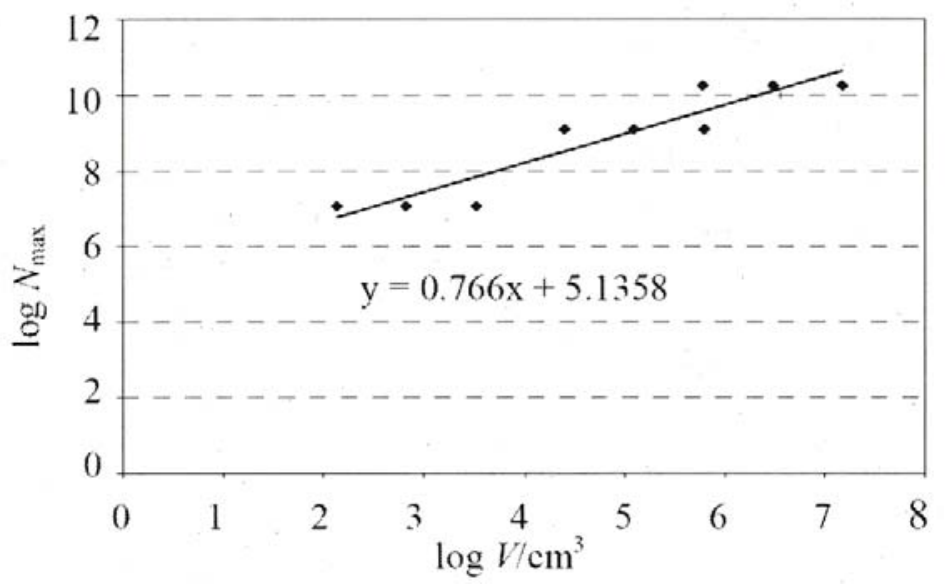

Figure 5: Volume effect on the maximum number of acoustic emissions.

\section{ROUTE TOWARDS CHAOS IN THE DYNAMICS OF CRACKED BEAMS}

项

he fourth and last topic is concerned with the dynamical behaviour of cracked beams (Carpinteri and Pugno $[40,10,11]$. Dealing with the presence of a crack in the structure, previous studies have demonstrated that a transverse crack can change its state (from open to closed and vice versa) when the structure, subjected to an external load, vibrates. As a consequence, a nonlinear dynamic behavior is introduced. This phenomenon has been detected during experimental testing performed by Gudmundson [41], in which the influence of a transverse breathing crack upon the natural frequencies of a cantilever beam was investigated. 
Several models have been proposed in the past for dealing with cracked vibrating beams [42-44], but, in all these models, the main assumption has been that the crack can be either fully open or fully closed during the vibration. Carpinteri and Pugno [10] recently developed a coupled theoretical and numerical approach to evaluate the nonlinear complex oscillatory behaviour in damaged structures under excitation. In their approach, they have focused their attention on a cantilever beam with several breathing transverse cracks and subjected to harmonic excitation perpendicular to its axis. The method, that is an extension of the super-harmonic analysis carried out by Pugno et al. [45] to subharmonic and zero frequency components, has allowed to capture the complex behavior of the nonlinear system, e.g., the occurrence of period doubling, as experimentally observed by Brandon and Sudraud [46] in cracked beams.

A pioneer work on period doubling was written in 1978, when Mitchell Feigenbaum [47] developed a theory to treat the route from ordered to chaotic States. Even if oscillators showing the period doubling can be of different nature, as in mechanical, electrical, or chemical systems, they all share the characteristic of recursiveness. He provided a relationship in which the details of the recursiveness become irrelevant, through a kind of universal parameter, measuring the ratio of the distances between successive period doublings, the so called Feigenbaum's delta. His understanding of the phenomenon was later experimentally confirmed [48], so that today we refer to the so-called Feigenbaum's period doubling cascade. However, even if the period doubling has a long history, only recently it has been experimentally observed in the dynamics of cracked structures [46].

To highlight the influence of the crack on the beam dynamics, let us consider two different numernical examples: a wikely nonlinear structure and a strongly nonlinear one. Only in the latter case the so called period doubling phenomenon clearly appears. Details about the beam geometry and materials can be found in [10]. For each of the two considered structures (Figs. 6a and $6 \mathrm{~b}$ ) the trajectory in the phase space is represented in Figs. $7 \mathrm{a}$ and $7 \mathrm{~b}$.

In a hypothetical linear structure, the structural response is linear by definition with obviously only one harmonic component at the same frequency of the excitation. In the weakly nonlinear structure of Fig. 6a, the response converges and it appears only weakly nonlinear. The trajectory in the phase diagram is close to an ellipse. The diagram is nonsymmetric as the spatial positions of the cracks (placed in the upper part of the beam). The trajectory is an unique closed curve since here the period of the response is equal to the period of the excitation.

(a)

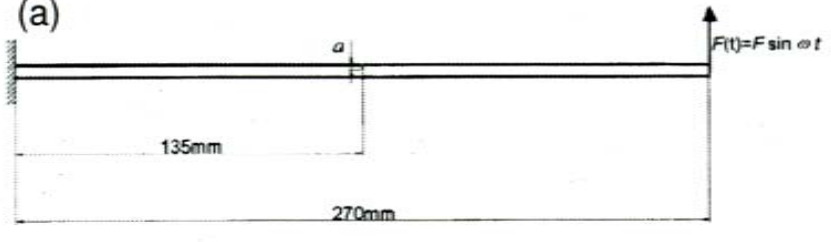

(b)

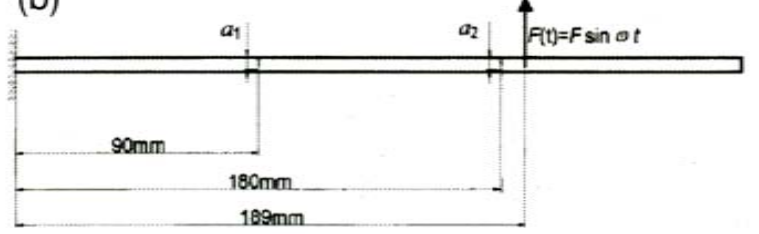

Figure 6: Damaged structures: weakly nonlinear (a) and strongly nonlinear (b).
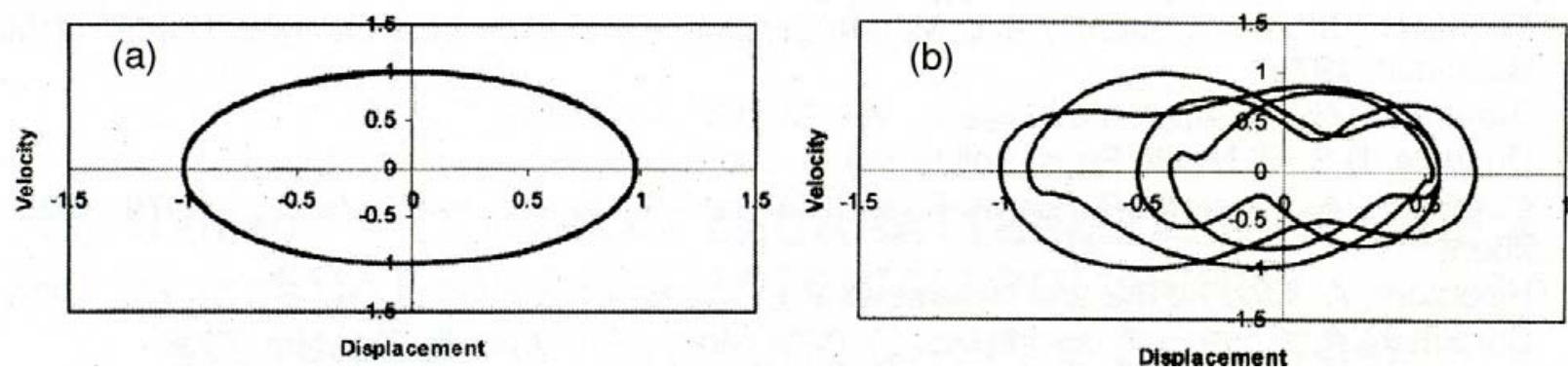

Figure 7: Dimensionless phase diagram of the response (free end displacement): weakly (a) and strongly (b) non linear structure.

In the strongly nonlinear structure of Fig. $6 \mathrm{~b}$ the nonlinearity increases. The harmonic components in the structural response are the zero one, the superharmonics as well as the subharmonic ones. It should be emphasized that a strong nonlinearity causes the period doubling of the response, i.e., the $\omega / 2$ component. The free-end vibrates practically with a period doubled with respect to the excitation. A nonnegligible component at $\omega / 4$ is observed too, representing a route to chaos through a period doubling cascade. The corresponding phase diagram clearly evidences this: the trajectory is composed by multiple cycles since here the period of the response is not equal to the period of the excitation. The 
distortions in the trajectory are consequences of the presence of the super- or subharmonics. Also in this case, the diagram is nonsymmetric as the spatial positions of the cracks.

This method is able to catch the transition toward deterministic chaos, like the occurrence of a period doubling, as shown in the numerical examples and experimentally observed in the context of cracked beam by Brandon and Sudraud [46].

\section{CONCLUSIONS}

7 he so-called "Complexity Sciences" represent a subject of fast-growing interest in the Scientific Community. They have entered also our more circumscribed Communities of Material Science and Material Strength, as the proposed examples may confirm. The presented topics were concerned with the structural behaviour of composite structures with snap-back instabilities (an example of cusp catastrophe), the occurrence of fractal patterns and geometrically self-similar morphologies in deformation, damage and fracture of heterogeneous materials, the apparent scaling in the nominal mechanical properties of disordered materials, the acoustic emission criticality in progressive structural collapse, the route towards chaos in the dynamics of cracked structures. As shown in these examples, the most interesting behaviors and phenomena can be synthetically interpreted only through the use of new and refined conceptual tools in the framework of "Complexity Sciences".

\section{ACKNOWLEDGEMENTS}

7 he authors would like to gratefully acknowledge the contributions made to this work by all members of the research group led by the senior author at the Department of Structural Éngineering and Geotechnics of the Politécnico di Torino. In particular, the warmest thanks go to Giuseppe Ferro, Nicola Pugno, Pietro Cornetti and Giuseppe Lacidogna. Support by the European Community is gratefully acknowledged by the authors. Thanks are also due to the Italian Ministry of University and Research (MIUR).

\section{REFERENCES}

[1] M.S. Garrido, R.Vuela Mendes, Complexity in physics and technology, World Scientific, Singapore, (1992).

[2] A. Carpinteri, S. Puzzi, Strength, Fracture and Complexity, 4 (2006) 189.

[3] A. Carpinteri, S. Puzzi, Strength, Fracture and Complexity, 4 (2006) 201.

[4] A. Carpinteri, in Application of Fracture Mechanics to Cementitious Composites, edited by S.P. Shah, Martinus Nijhoff Publishers, Dordrecht, (1985) 287.

[5] A. Carpinteri, J. Mech. Phys. Solids, 37 (1989) 567.

[6] A. Carpinteri, Int. J. Frac., 44 (1990) 57.

[7] A. Carpinteri, Mech. Mater., 18 (1994) 89.

[8] A. Carpinteri, Int. J. Solids Struct., 31 (1994) 291.

[9] A. Carpinteri, G. Lacidogna, N. Pugno, Engng. Frac. Mech., 74 (2007) 273.

[10] A. Carpinteri, N. Pugno, J. Appl. Mech., 72 (2005) 511.

[11] A. Carpinteri, N. Pugno, J. Appl. Mech., 72 (2005) 519.

[12] R. Thom, Structural Stability and Morphogenesis: an Outline of a General Theory of Models. Benjamin (1975).

[13] G. I. Barenblatt, J. Appl. Math. Mech., 23 (1959) 622.

[14] D. S. Dugdale, J. Mech. Phys. Solids, 8 (1960) 100.

[15] A. Carpinteri, P. Cornetti, F. Barpi, S. Valente, Engng. Frac. Mech., 70 (2003) 1809.

[16] A. Hillerborg, M. Modeer, P.E. Petersson, , Cement Concr. Res., 6 (1976) 773.

[17] A. Carpinteri, P. Cornetti, S. Puzzi, Appl. Mech. Rev., 59 (2006) 283.

[18] A. Carpinteri, Int. J. Solids Struct., 25 (1989) 407.

[19] A. Carpinteri, Engng. Frac. Mech., 32 (1989) 265.

[20] Determination of the fracture energy of mortar and concrete by means of three-point bending tests on notched beams. Technical Report 18, Materials and Structures, R.I.L.E.M. (1985).

[21] L. Biolzi, S. Cangiano, G.P. Tognon, A. Carpinteri, Mater. Struct., 22 (1989) 429.

[22] B.B. Mandelbrot, The Fractal Geometry of Nature. New York: Freeman (1982). 
[23] A. Carpinteri, G. Ferro, Mater. Struct., 28 (1994) 563.

[24] A. Carpinteri, G. Ferro, Mater. Struct., 31 (1998) 303.

[25] A. Carpinteri, B. Chiaia, P. Cornetti, Eng. Frac. Mech., 69 (2002) 207.

[26] A. Carpinteri, B. Chiaia, K.M. Nemati, Mech. Mater., 26 (1997) 93.

[27] A. Carpinteri, B. Chiaia, S. Invernizzi, Theor. Appl. Frac. Mech., 31 (1999) 163.

[28] C.F. Richter, , Elementary Seismology, W.H. Freeman \& Company, San Francisco and London (1958).

[29] H. Rusch, , Zement-Kalk-Gips (Wiesbaden), 12 (1959) 1.

[30] R.G. L'Hermite, in Proc. 4th Int. Symp. on Chemistry of Cement, V-3. NBS Monograph 43, NBS, Washington DC, (1960) 659.

[31] G. S. Robinson, in Proc. Int. Conf. on the Structure of Concrete and Its Behavior Under Load, Cement and Concrete Association, (1965) 131.

[32] W. M. McCabe, R. M. Koerner, A. E. Jr. Load, , ACI Journal, 13 (1976) 367.

[33] P. Shah, L. Zongjin, , ACI Mater. J., 91 (1994) 372.

[34] M. Ohtsu, , Magazine Concr. Res., 48 (1996) 321.

[35] A. Carpinteri, G. Lacidogna, in Proc. of STREMAH VII (Bologna, 2001), WIT Press, Southampton, (2001) 327.

[36] A. Carpinteri, G. Lacidogna, Italian Patent N. To 2002 A000924, deposited on 23 October 2002.

[37] A. Carpinteri, G. Lacidogna, N. Pugno, in Fracture Mechanics of Concrete and Concrete Structures (Proceedings of the $5^{\text {th }}$ International FraMCoS Conference, Vail, Colorado, USA, (2004), edited by V.C. Li et al., 1 (2004) 31.

[38] A. Carpinteri, N. Pugno, Magazine Concr. Res., 54 (2002) 473.

[39] A. Carpinteri, N.Pugno, Int. J. Numer. Anal. Methods Geomech., 26 (2002) 499.

[40] A. Carpinteri, N. Pugno, Proceedings of the $9^{\text {th }}$ International Congress on Sound and Vibration, Orlando, USA, CDROM, (2002) paper N. 114.

[41] P. Gudmundson, J. Mech. Phys. Solids, 31 (1983) 329.

[42] M.I. Friswell, J. E. T. Penny, in Proc. X Int. Modal Analysis Conf., (1992) 516.

[43] W. Ostachowicz, M. Krawczuk, Comput. Struct., 36 (1990) 245.

[44] R. Ruotolo, C. Surace, P. Crespo, D. Storer, Comput. Struct., 61 (1996) 1057.

[45] N. Pugno, C. Surace, R. Ruotolo, J. Sound Vib., 235 (2000) 749.

[46] J. A. Branden, C. Sudraud, , J. Sound Vib., 211 (1998) 555.

[47] M. J. Feigenbaum, J. Stat. Phys., 19 (1978) 25.

[48] P.S. Linsay, Phys. Rev. Lett., 47 (1981) 1349. 